\title{
Resistencias a la introducción del sorteo entre el asamblearismo y la institucionalización: el caso de Podemos Cádiz ${ }^{*}$
}

\author{
Resistances to the Introduction of Sortition between Assemblies \\ and Institutionalisation: The Case of Podemos in Cádiz
}

JORGE COSTA DELGADO**

\begin{abstract}
Resumen: La intención de este artículo es estudiar las resistencias a la introducción del sorteo en una agrupación política donde este tema era una novedad. Esto tuvo lugar en un momento especialmente delicado e inestable para la agrupación, ya que se enfrentaba con posibilidades de éxito a sus primeras elecciones municipales. ¿Cómo fue el proceso? ¿Qué tipo de resistencias hubo? ¿Qué ocurrió finalmente con las propuestas que incluían el sorteo? Se responderá a estas preguntas a través de cuatro momentos del proceso, atendiendo a la relación entre la posición en la agrupación de los sujetos implicados y los argumentos esgrimidos en el debate.
\end{abstract}

Palabras clave: Sorteo, Filosofía Política, Etnografía, Podemos, Participación Ciudadana

\begin{abstract}
The intention of this article is to analyse the resistances to the introduction of sortition in a political group where this subject was a novelty. This happened in a specially delicate and unstable moment for the group, since it was facing its first local elections with chances of success. How did the process go? Which were the resistances? What did finally happen with the sortition proposals? These questions will be answered through four moments of the process, according to the connection between the concerned subjects' position in the group and the arguments used in the discussion.
\end{abstract}

Keywords: Sortition, Political Philosophy, Ethnography, Podemos, Citizen Participation

\section{Introducción}

Desde la década de 1970, el sorteo ha vuelto a formar parte progresivamente del menú de posibilidades políticas concebibles y practicables, después de un eclipse que ha durado dos siglos. En el caso de España, ya en la primera década del siglo XXI, se pusieron en práctica experiencias aisladas de grupos de personas sorteadas con funciones consultivas

Fecha de recepción: 15/05/2017. Fecha de aceptación: 22/08/2017.

* Este trabajo forma parte del proyecto de investigación: "La recepción de la Filosofía grecorromana en la Filosofía y las Ciencias Humanas en Francia y España desde 1980 hasta la actualidad” (FFI2014-53792-R).

** Investigador en la Universidad de Cádiz. Líneas de investigación: Sociología política, Filosofía política, Sociología de la filosofía, Sociología del conocimiento, Filosofía española contemporánea, Historia intelectual. Publicaciones recientes: Dowlen, Oliver y Costa Delgado, Jorge: El sorteo en política: cómo pensarlo y cómo ponerlo en práctica, Editorial Doble J, Sevilla, 2016; Costa Delgado, Jorge: "El ethos universitario en los filósofos de la Generación del 14", Isegoría, 52, 2015, pp. 245-265.

Contacto: jorge.costa@uca.es 
(Sintomer, 2011, 147-148; Ganuza, 2011, 161-176; Blanco, 2005), aunque no tuvieron demasiada repercusión. Unos años más tarde, después del ciclo de movilizaciones posterior al 15-M, donde una de las principales demandas fue la de una mayor democracia en la esfera política, el sorteo tuvo cierta relevancia en los debates organizativos y políticos surgidos en torno al nacimiento del partido político Podemos, en 2014. Pocos meses después de su fundación, en la Asamblea Ciudadana Vistalegre I de octubre, donde se decidió su estructura organizativa, la principal propuesta que agrupaba la oposición al equipo Claro Que Podemos -liderado por Pablo Iglesias e Íñigo Errejón y que se impuso con mucha diferencia- incluía en su programa la selección por sorteo de representantes internos al partido. Este equipo -Sumando Podemos- producto de una coalición de actores y grupos diversos entre los que se encontraba "Anticapitalistas", corriente hegemónica en Cádiz, se disolvió poco después de Vistalegre I. La etnografía que sirve de base a este artículo comienza en febrero de 2015. En ella he tratado de estudiar, en las condiciones que describiré a continuación, los efectos de la introducción del sorteo en la agrupación local de Podemos Cádiz en un momento muy especial, ya que esta afrontaba una campaña electoral que podía desembocar en su acceso a las instituciones públicas. El artículo, por lo tanto, aborda un caso particular de un fenómeno general: los efectos que genera en el campo político actual la percepción de la potencial distorsión que introduce el sorteo ${ }^{1}$. El hecho de que la etnografía estudiara una agrupación en transición desde el asamblearismo a la institucionalización es relevante, ya que se trata de un momento en que se cuestionaron algunos de los supuestos que estructuraban la agrupación, ante la necesidad de adaptarse a una nueva circunstancia. Por ello, pueden identificarse claramente qué principios orientaron la decisión en determinados aspectos para los que el sorteo ofrecía soluciones alternativas. Además, la transformación sufrida por la agrupación permite observar las resistencias al sorteo formuladas desde distintas posiciones del campo político, a veces por los mismos sujetos. Por último, las propiedades de los sujetos a las que hago referencia en este artículo tienen que ver con su posición política en la agrupación, aunque la etnografía asume una perspectiva más amplia que no tiene cabida aquí.

El artículo consta de cuatro apartados que recogen cuatro momentos de la evolución de la agrupación de acuerdo a la cuestión estudiada, precedidos de una reflexión sobre el lugar del investigador frente al proceso. Al final, en las conclusiones, se propone una tipología de las resistencias frente al sorteo que se describen a lo largo del artículo.

\section{El observador ante el proceso: ¿qué condiciones posibilitan y limitan la observación?}

Quisiera comenzar la exposición explicando mi propia posición ante el proceso. Sin objetivarla, o al menos sin intentar hacerlo, no se comprenden bien las condiciones de posibilidad de una observación de este tipo, que implica acceder a espacios y relaciones que no están al alcance de cualquier investigador o, al menos, no de la manera en que dicho acceso se me presentó. Al mismo tiempo, esta posición indudablemente tuvo efectos sobre el propio proceso que estudié y sobre la perspectiva desde la que afronté dicho estudio. Todo ello requiere cierta reflexión.

1 Para mayores precisiones sobre los argumentos a favor del sorteo, el lector puede acudir a varios artículos de este mismo monográfico que se extienden sobre el tema. 
Para ello, un primer obstáculo que hay que salvar es la incomodidad ante la exposición pública de mi propia implicación en el proceso, teniendo la cautela de no convertir una exposición que aspira a ser científica en la exhibición de una peripecia personal. Considero que este pudor no es solo la expresión de una sana intención de preservar un espacio para la intimidad, que no debe mezclarse con la filosofía o la sociología, ni tampoco un pudor intelectual, que está obligado a seleccionar la información más relevante para construir una narración razonada de aquello que pretende explicar. Creo que, al menos en parte, este pudor expresa también una resistencia a objetivar mi propio lugar como sujeto activo en el proceso y, al hacerlo, a perder el privilegio de la posición del científico que enuncia la objetividad del mundo social.

En primer lugar, es importante tener en cuenta que esta etnografía y los distintos pasos que se van dando en ella no son producto de una decisión meditada previa de carácter científico. La lógica de mi actuación en este proceso tiene, ante todo, un sentido político; aunque la sensibilidad intelectual no pueda disociarse de la política y aunque en algunos momentos del proceso, especialmente al final, el interés intelectual se convirtiera en el principal estímulo para mantener el compromiso político -en este sentido, un compromiso también con la investigación-. Esta circunstancia puede considerarse, sin duda, un lastre importante desde el punto de vista científico: no disponer de una mínima planificación sobre el acercamiento al objeto de estudio impide ver aquello que no se sabe que se está buscando. Pero, por otra parte, la vía de inserción política permite el acceso a espacios políticos restringidos a los investigadores que, de acceder a ellos como tales, se modificarían sustancialmente: por ejemplo, aunque un sociólogo recibiera permiso de un partido para observar el funcionamiento de un equipo de campaña electoral, este no se comportaría de igual manera cuando sintiera que está siendo observado por una instancia externa al mismo. Este efecto, que se manifiesta en cualquier investigación, es especialmente notable en aquellos espacios sociales más reluctantes a ser objetivados. Mi trayectoria militante previa en la ciudad, así como vínculos políticos y personales con personas muy activas y con peso en la agrupación me permitieron una rápida integración en la misma. Gracias a ello, tenía un capital simbólico - político, específicamente- acumulado previamente a aquel que pudiera derivarse de mi implicación efectiva en el proceso. Esta trayectoria militante previa me vinculaba específicamente al núcleo político de la agrupación que iba a estudiar, con conflictos y desencuentros, pero también con el reconocimiento del trabajo realizado en espacios y proyectos compartidos. Como explicaré más adelante, esto no solamente fue una condición para el acceso y la permanencia en la agrupación, sino para que la propia cuestión del sorteo pudiera llegar a plantearse públicamente y ser escuchada.

En segundo lugar, ese compromiso político -entendido específicamente con la agrupación local de Podemos Cádiz- debía conjugarse con un compromiso con otros ámbitos de mi existencia que se vieron afectados por la política: diversas tareas académicas, una tesis doctoral sobre un tema distinto, mis relaciones personales y familiares... Todas estas actividades fueron, según el momento y el grado de intensidad, más o menos compatibles con el compromiso político. En cualquier caso, es importante tener en cuenta que estas actividades suponían un estímulo intelectual y emocional fuera de la política y que, aunque algunas de ellas fueran relegadas temporalmente, siempre permanecieron como un espacio de referencia alternativo a la política. Esto me permitió una cierta distancia con 
la agrupación local, dentro de mi implicación, y con los referentes ideológicos y personales dominantes en ella. A esto se sumaba que, por entonces, mi compromiso político personal estaba temporalmente limitado: no era residente fijo en la ciudad a largo plazo y no sabía dónde iba a estar después de la campaña; lo que fue muy importante de cara a mi posición como observador del proceso: no estaba tan atado como quienes vivían su compromiso político con esta agrupación concreta a largo plazo o como aquellos para los que la agrupación era un espacio de sociabilidad prácticamente insustituible. Estas personas eran más susceptibles de asumir las coacciones verticales de la organización como un dato inalterable o soportable y estaban menos dispuestas a arriesgar su posición y su futuro político -y personal- en conflictos abiertos, a cuestionar los supuestos que fundaban la cohesión interna del grupo y, por último, a aceptar un mayor grado de incertidumbre respecto al futuro inmediato del proyecto. La introducción de perspectivas profanas y la incertidumbre, inherentes al sorteo, atentaban contra este sentido común de la organización. Esto no me sitúa en la imagen clásica, corporativista y reconfortante, del intelectual que ve comprometida su independencia de criterio al comprometerse con un partido político, sino en la posición de un sujeto que tiene espacios sociales de referencia que no están subordinados al campo político.

Por último, queda la cuestión ética: ¿es legítimo apropiarse de este conocimiento para exponerlo como una investigación personal? ¿no es expropiar una experiencia colectiva en beneficio individual? En este aspecto creo que la objetivación etnográfica no se diferencia de los análisis políticos tan frecuentes dentro del campo. Se trata tan solo de la legítima expresión de una perspectiva de un proceso político del que yo también formé parte, cuyo relato no pertenece en exclusiva a nadie.

\section{Una primera propuesta: grupos de discusión en pre-campaña}

La primera propuesta relacionada con el sorteo, aunque de manera indirecta, la presenté en una de las primeras asambleas a las que me incorporé, en febrero de 2015. Las elecciones, conviene recordarlo, se celebraron el 24 de mayo del mismo año. La propuesta consistía en organizar, con la colaboración de personas de la asamblea, varios grupos de discusión para tener algún material que informara sobre diagnósticos, demandas y modos de participación política en la ciudad. El objetivo era recabar información procedente específicamente de personas ajenas a entornos ya politizados, ya que la relación con estos estaba bien cubierta por los militantes del partido. La propuesta tenía dos puntos en común con el sorteo: el recurso a personas seleccionadas relativamente al azar y la promoción de una perspectiva profana al campo político. Presentamos la propuesta dos personas ante la asamblea, en dos ocasiones, y después por escrito ante el órgano ejecutivo -el Consejo Ciudadano-. La propuesta nunca recibió respuesta formal: la asamblea estaba inmersa en un conflicto interno y no incorporó la votación a ninguno de los órdenes del día. Sin embargo, sí hubo un argumento en contra cuando se presentó en la asamblea: "le falta contenido político". Más adelante, en privado, otra persona intentó disculpar el desinterés de la asamblea por la propuesta: "vienen muchos locos y frikis y la gente no se fía de quienes no conoce". Ambos argumentos expresaban la resistencia del campo político que 
se protegía contra el saber profano. Una defensa que se dirigía contra contenidos -unos marcados como políticos, definidos arbitrariamente por quienes están en el campo, y otros degradados, sin derecho a ser abordados en ese espacio- y contra las personas que los enunciaban: si no te conocen y no propones algo similar a lo que el espacio reconoce como legítimo, no eres reconocido como interlocutor válido.

Foucault -sigo en esto a José Luis Moreno Pestaña (2011)- señalaba cuatro condiciones para ejercer la palabra libre en la democracia ateniense: garantías jurídicas, prestigio, la verdad de la opinión defendida -conforme a la experiencia de quien la enuncia- y coraje. Obviando las condiciones materiales, para las que no dispongo de espacio en este artículo, aunque son una parte imprescindible de la etnografía, podemos analizar a partir de estos cuatro elementos la primera fase de mi inserción en la agrupación:

1. La asamblea era un espacio formalmente abierto, donde se recogían y debatían propuestas. No existía, en el ámbito local, un espacio político diferenciado con mayor peso, por lo que se daban las garantías jurídicas mínimas para la palabra libre. Sin embargo, la autonomía del órgano ejecutivo para decidir qué era o no relevante de cara a su inclusión en el orden del día dificultaba que personas que no tenían influencia directa en él pudieran conseguir que se debatiera y aprobara el tema deseado.

2. No todas las personas asistentes a la asamblea me reconocían el prestigio necesario para hablar en ella, lo que potencialmente me descartaba como sujeto político: loco, friki, ignorante o incompetente.

3. La verdad de una opinión, en el sentido en que la menciona Foucault a propósito de la parresía, tiene que ver con la racionalidad y con la conformidad del discurso con la experiencia de quien lo enuncia. Ambos rasgos están estrechamente vinculados al prestigio: la experiencia solo es demostrable ante un público que te conoce -"la gente no se fía de quien no conoce"- y la racionalidad siempre está contextualizada. En una asamblea política, solo se reconocerá como racional aquel discurso que conecte con los referentes legítimos en ese espacio, o bien cuyo portador cuente con prestigio suficiente como para avalar la ruptura de esas prácticas -habría mucho que decir al respecto sobre la propia fundación de Podemos-. Sin ese prestigio y sin una socialización previa en espacios sociales tan homogéneos como la militancia de extrema izquierda, es fácil en una primera aproximación ser ubicado en uno de los dos límites que Jesús Ibáñez $(1986,59)$ definía a propósito precisamente de los grupos de discusión: el loco, al que nadie entiende, y el tonto, que solo repite lugares comunes.

4. El coraje puede entenderse como la posibilidad de sobreponerse a un entorno desfavorable. En mi caso, gracias a que contaba con otros espacios sociales de referencia, a una socialización política previa y a que sabía de otras personas en la asamblea que no compartían esa descalificación.

Una primera lección se impone: la introducción de propuestas que, como el sorteo, implican una ruptura respecto a las prácticas hegemónicas en un espacio político requiere alguna forma de prestigio que las sostenga. En el caso de Cádiz, como explicaré más 
adelante, acabó siendo mi trayectoria militante previa, las redes personales que tenía en la asamblea gracias a ella, mi posición como responsable del programa electoral y, en menor medida, mi condición de profesor universitario. La primera vez que se propuso el sorteo dentro de Podemos, antes de Vistalegre I (octubre de 2014), la legitimidad que sostuvo las propuestas procedía de la brecha abierta por el recurso a herramientas telemáticas en internet para las votaciones plebiscitarias, que permitió que un pequeño grupo organizado se aprovechara de su pericia en el manejo de esta tecnología en un espacio escasamente regulado que las redes militantes no controlaban bien, logrando cierta visibilidad mediática. A ellos se sumaron algunos apoyos procedentes del mundo militante y académico aglutinado en torno a Podemos, entre los que me encontraba, configurando el grupo "Profundización democrática". Más tarde, en distintas elecciones regionales a órganos internos del partido, el sorteo ha formado parte de algunas de las propuestas en disputa: Andalucía (noviembre, 2016), Comunidad Valenciana (mayo, 2017) y Murcia (junio, 2017). En estos tres casos, fueron personas ya integradas en el aparato o con cargos de representación quienes lo promovieron, apoyándose en otras corrientes y logrando en la Comunidad Valenciana y Murcia un pequeño espacio para el sorteo. En todo caso, resulta evidente la dificultad fundamental de una aplicación democrática del sorteo: para poder tener cierta relevancia pública -no digamos ya éxito- cualquier propuesta que lo incluya debe apoyarse en un prestigio labrado en espacios políticos cuya afirmación se construye precisamente contra el tipo de conocimiento profano y el anonimato que promociona el sorteo. En definitiva y simplificando mucho: si uno ha logrado consagrarse políticamente en un determinado espacio, ¿por qué promover una medida que socavaría las condiciones que permiten mantener y reproducir esa consagración? Parece que, hasta ahora, en algunos sitios, el sorteo ha logrado integrarse en el discurso de democratización o apertura del espacio político que supone una importante fuente de legitimidad para las distintas corrientes en un contexto de disputa por los órganos del partido, especialmente para aquellas que se encuentran en la oposición ${ }^{2}$. Curiosamente, no parece que se haya considerado el uso "liberal" del sorteo para controlar los efectos negativos de la lucha de facciones, presente en ejemplos históricos -la Florencia de Maquiavelo, por ejemplo, un pensador muy citado en Podemos- y contemporáneos -el partido Morena en México (López-Guerra, 2015)- y que respondería a uno de los problemas más visibles de Podemos.

2 Un evaluador, a quién agradezco enormemente la observación, propone el caso de Cádiz como un ejemplo de caso crítico para la confirmación de una teoría (siguiendo a Eckstein, 1975): dado que Anticapitalistas, corriente hegemónica en Cádiz, se sitúa en el polo más izquierdista o movimientista dentro de Podemos, teóricamente debía ser más favorable a una implementación radicalmente democrática del sorteo. La etnografía muestra que Anticapitalistas en Cádiz pasa por todas las posiciones del arco político definido en este artículo: asamblearismo extra-institucional, partido centrado en la lucha electoral y mediática y gestor inmerso en la lógica institucional. Las resistencias al sorteo aparecen en todas las fases, modulándose de acuerdo a cada posición. Por tanto, tomado como caso crítico en cuanto al sorteo, lo que este artículo muestra parece extrapolable al conjunto del campo político. Mucho más habría que decir sobre la inercia del campo político y las constricciones que impone a quienes se integran en él, al margen de sus intenciones y del discurso que tengan sobre sí mismos. 


\section{Segundo hito: el sorteo como elemento central de la participación ciudadana en el programa electoral}

En el momento de la elaboración del programa electoral, unas semanas después, mi posición era diferente: había sido elegido responsable de la coordinación del mismo. Desde esta posición de poder -responsable de la coordinación del programa, promocionado por "Anticapitalistas" y por personas con prestigio en la agrupación, con una trayectoria militante previa que se empieza a reconocer y con un capital cultural legítimo en ese espacio- pude enunciar una serie de propuestas que pretendían situar al sorteo, combinado con otros procedimientos, en el centro de un sistema de participación ciudadana municipal. No me detendré sobre su contenido, que puede consultarse en el programa electoral de Por Cádiz Sí Se Puede (2015) y en una publicación posterior (Dowlen y Costa, 2016), donde aparecen estas propuestas más desarrolladas y acompañadas de argumentos y comentarios sobre su potencial implementación. Me centraré en cambio en las reacciones ante el sorteo.

La primera discusión tuvo lugar en la comisión de participación ciudadana, un paso previo a la discusión del programa en la asamblea general. La posición de la mayoría de la comisión consistía en defender un sistema tradicional de participación de asambleas y delegados con base territorial y el sorteo se aceptó sin que existiera una deliberación real: se trató más bien de una negociación ${ }^{3}$, en la medida en que se entendió que ambos sistemas no eran incompatibles. La primera exposición general del sorteo en la agrupación se hizo en una de las dos asambleas dedicadas al programa: con muy poco tiempo para la exposición y debate y, no obstante, con un ambiente muy favorable a pasar cualquier propuesta avalada por alguien conocido de la asamblea. Mi posición en la agrupación, como digo, había cambiado: mis propuestas ya no podían ser catalogadas públicamente como "no políticas". Además, conté con el apoyo inesperado de una persona importante en la agrupación. Los argumentos en contra, consecuentemente, fueron diferentes en esta ocasión:

1. El primero iba en la línea de la descalificación de lo profano como "no político", solo que esta vez la crítica no se dirigió a la persona que defendía la propuesta, sino al tipo de sujetos que promociona el sorteo. La crítica se puede enunciar en una forma más burda: "puede salir un loco o un nazi", apelando a un umbral de racionalidad pura o a una ideología supuestamente compartidos por los presentes; o bien en una forma más elaborada, reafirmando el principio de distinción que tiene una ilustre y transversal tradición en la Modernidad (Manin, 1998, 119-163), descalificando a la ciudadanía no politizada por incompetente y postergando su incorporación a un futuro indefinido, cuando hubieran adquirido una cultura política apropiada. Esto remite, en el fondo, a los mismos umbrales que el argumento anterior: "es una propuesta interesante, pero la gente no está preparada para eso, debe ser una tarea más a largo plazo, primero tenemos que conseguir que se vayan acostumbrando a lo que queremos hacer". En ambos casos el argumento contra el sorteo se basa en afirmar una comunidad política cerrada frente al exterior.

3 En esta distinción sigo a Urfalino (2013). 
2. El segundo argumento no iba dirigido específicamente contra el sorteo, sino contra la remuneración de los participantes seleccionados por este procedimiento. Esta crítica da cuenta de dos cosas: la limitada conciencia de las barreras sociales -especialmente de clase- existentes para la participación política, algo muy extendido en el mundo militante, y el escaso grado de institucionalización de la agrupación en ese momento. Había pocas personas en la asamblea que hubieran ejercido ocupaciones remuneradas en la política y solo uno de los presentes -quizás dos, al menos que yo tenga noticia- era un liberado sindical en aquel momento. Después de la entrada en el gobierno de la ciudad, con la remuneración de concejales, cargos de confianza y asesores, era difícil que pudiera rechazarse la remuneración para el sorteo; aunque sí podía apelarse a la escasez de fondos, como ocurrió en otro momento. El argumento revela una ideología de la libre participación y el voluntarismo muy vaga, del tono que se expresaba públicamente en las asambleas del 15-M, que sostenía, como decía un militante en otra reunión, que "cuantas menos normas haya y más abierta sea la asamblea, más se estimula la participación”.

En definitiva, estos dos argumentos contra el sorteo muestran una forma de repliegue del campo político sobre sí mismo, concretamente sobre una posición particular dentro de él: la de la militancia de izquierda extra-institucional. La propuesta pasó una primera votación con tantos votos a favor como abstenciones, por lo que, a propuesta mía, se postergó la decisión a una segunda sesión: la última de elaboración del programa participativo, donde la enorme acumulación de propuestas pendientes y la tendencia a evitar los conflictos que se fueron planteando durante la sesión, hizo que se aprobara sin oposición, remitiendo al futuro posibles modificaciones. Aunque desde el equipo de campaña me pidieron que, sin alterar el contenido de las propuestas, no incluyera la palabra sorteo en la redacción definitiva del programa, entendiendo que podía ser utilizada mediáticamente por la oposición.

\section{Tercer hito. El sorteo en el Ayuntamiento: la colaboración con la concejalía de Participación Ciudadana}

En julio de 2015, después de un mes ausente de la ciudad y de la victoria de Podemos en las elecciones municipales, me incorporé de nuevo a la asamblea. Por iniciativa propia y por recomendación de la persona responsable de coordinar las relaciones entre la agrupación y el grupo municipal, comencé a colaborar con el concejal de Participación Ciudadana. En este punto, se impuso mi condición de "experto" en participación, establecida en un momento excepcional y fundada en una posición y en recursos que no tenían que ver estrictamente con mis conocimientos sobre la materia ni tampoco con el hecho de compartir la visión más extendida sobre participación ciudadana en la asamblea. Era el concejal el que, a discreción, convocaba reuniones y decidía quien acudía a ellas, con la eventual colaboración de alguno de los asesores. Por otra parte, tampoco había plena confianza entre los dirigentes -había opiniones divididas o un interés parcial- en el proyecto que yo defendía y algunos trataron de recurrir a otros "expertos". El momento post-electoral fue muy caótico: el concejal tenía 
un programa poco desarrollado y sin contrastar con las posibilidades del Ayuntamiento ni con la nueva coyuntura política abierta después de las elecciones; además, no disponía de técnicos municipales ni tenía la posibilidad de contratarlos a corto plazo. La respuesta fue similar a la que se dio en otras áreas de gobierno: buscar especialistas entre las redes personales y políticas de los concejales y de los dirigentes que controlaban el proceso de contratación. En aquellas áreas en las que no se optó por personal remunerado, el control lógicamente fue mucho más laxo -como fue mi caso-: había menos capacidad de atraer a especialistas en la materia con compromiso de permanencia.

En esa época, a finales del verano (27 de agosto), asistí a una reunión con el concejal, un asesor municipal -militante de la agrupación especialmente contrario al sorteo- y un representante de una empresa consultora para temas de transparencia, cuyo desarrollo bien puede leerse como una competición por erigirse en experto de referencia en participación municipal con el concejal como espectador. El miembro de la consultora -que acudía teóricamente para hablar de transparencia, no sobre participación- y el propio asesor del ayuntamiento - un militante de la agrupación desde su fundación- interrumpieron mi exposición apenas después de haber comenzado, planteando algunas críticas que pueden clasificarse en función de quien las enunciaba:

\section{Repliegue sobre una posición específica del campo político: el militante asesor municipal}

"Los consejos sorteados no garantizan un espacio para los partidos políticos en las decisiones"

Esta crítica guarda una estrecha relación con la posición de quien la enunciaba: el asesor municipal, con una larga trayectoria en organizaciones políticas, había sido una de las personas responsables de la contratación de personal en la agrupación. $\mathrm{Su}$ control de la asignación de retribuciones, logrado gracias a su afinidad con los dirigentes y a su experiencia burocrática previa -que hacía ver frecuentemente en sus intervenciones públicas con una jerga legalista acorde a lo que de esa posición se esperaba-, y, por tanto, su posición política privilegiada quedaban en entredicho en un sistema que cuestionaba la legitimidad como agente político exclusivo de la estructura burocrática que las sostenía. En el modelo representativo español, los partidos tienen el monopolio de la actividad política institucional. Las cámaras sorteadas, tal y como estaban planteadas en el programa, preservaban pequeños espacios para una acción política ciudadana independiente de los partidos, aunque estos tenían cabida en el proceso. Cualquier intento de introducción del sorteo tiene que enfrentarse, con muy pocas oportunidades, a las resistencias que genera el cuestionamiento de ese monopolio partitocrático: por pequeño que sea el espacio, abre la posibilidad de experimentar la posibilidad de una política institucional sin la mediación de los partidos. Con frecuencia este temor a la pérdida de control político por parte de los partidos se expresa proyectándolo sobre otros partidos, no sobre el propio. Es decir, se presenta el argumento como el miedo a que otro tenga demasiada influencia, no a tenerla uno mismo. 
"La izquierda es minoritaria en la ciudad y la posibilidad estadística de que militantes del PP y del PSOE puedan entrar en un consejo por sorteo es más alta. Esto, dado el mayor peso de personas con militancia política en la discusión, puede inclinar el órgano a su favor y no nos podemos permitir ese riesgo".

La objeción carece de cualquier fundamento estadístico y, en todo caso, es salvable con un sistema de vetos o recusaciones previas al sorteo. Lo interesante de este argumento es que se sostenía al mismo tiempo que un gobierno en minoría estaba llevando a cabo una política basada en una estrategia discursiva obligada a jugar en un terreno que se reconocía como absolutamente parcial y hostil: los medios de comunicación. El riesgo potencial, estadísticamente insignificante, de que la opinión de un militante de derechas pueda condicionar la deliberación de una cámara sorteada es infinitamente menor que el riesgo real de que la propiedad de los medios de comunicación condicione la deliberación ciudadana mediante la facturación de una opinión pública sesgada -riesgo que el propio interlocutor, el militante asesor, reconocía e incluso exageraba, negando cualquier autonomía relativa a los periodistas-. Mientras tanto, en la agrupación y en el discurso público se seguía defendiendo una política basada en la toma de conciencia a través de la experiencia de la lucha social, pese a que en la ciudad se asistía a un panorama de desmovilización social. De ello se derivaba una estrategia de intervención consistente en acudir a los escasos espacios sociales donde ya se había declarado un conflicto político abierto. Los recursos propios de la agrupación eran insuficientes y los recursos institucionales a los que esta accedió al llegar al Ayuntamiento se destinaron paradójicamente a una estrategia mediática en las condiciones adversas anteriormente descritas (al menos 7 de 13 asesores dedicados a difusión en medios de comunicación y redes sociales).

¿Cuál era el sentido entonces del argumento? Se prefiere la ficción de racionalidad de la estrategia mediática, aunque se limite al control parcial de las condiciones de la emisión del mensaje, a la incertidumbre de una apertura del campo político. Las élites políticas, en este caso de izquierda, no quieren renunciar a su cuota de poder en la definición de lo político -aunque sea reducida: son dominados en un campo político donde el peso del capital económico es enorme en los medios de comunicación- cediendo espacios de deliberación y decisión a profanos, a quienes consideran alienados y fácilmente manipulables.

\section{"No es el momento adecuado"}

Una forma de evitar la cuestión del sorteo sin llegar a una confrontación abierta es el aplazamiento. En la reunión, el militante asesor sugirió en dos ocasiones elaborar un orden de prioridades donde el sorteo quedaría relegado indefinidamente, sin desaparecer del programa, pero sin enunciarse tampoco como tal. El mismo argumento reaparecía en otros contextos, donde se defendía que había asuntos más importantes que el sorteo o la participación en general, sin cuestionar quién decidía el orden de prioridades. En otra reunión, este mismo asesor argumentó a favor de la exclusión de 
alguna de las herramientas de participación por su excesiva complejidad y número, apelando a dificultades técnicas de gestión que eran competencia del personal del Ayuntamiento. Dado que la exclusión apuntaba arbitrariamente a las herramientas que incluían el sorteo, pedí información sobre estas dificultades, pero nunca se me presentó. El aplazamiento de cuestiones conflictivas era una práctica ya habitual en la asamblea previamente a la entrada en el Ayuntamiento; sin embargo, la posición institucional introduce una novedad muy importante: el aplazamiento se refuerza con una definición de lo posible formulada desde lo institucional, desde quien controla los recursos institucionales hacia quien no dispone de información para cuestionar su disponibilidad ni de medios o canales para exigir esta información.

"La oposición y los medios de comunicación pueden utilizar el sorteo en nuestra contra”

El argumento de la oportunidad mediática supone un repliegue sobre una estrategia comunicativa de defensa de la posición institucional. Ya se esgrimió durante la campaña electoral para evitar que apareciera la palabra sorteo en el programa, que no fue la única que se evitó, respondiendo a la presión que supone convertirse en una alternativa real en el juego electoral. Una vez en el gobierno, el argumento pasó a ser que el sorteo podía ser utilizado mediáticamente por la oposición para atacar al Gobierno: era imprudente abordarlo en la situación de debilidad en la que este se encontraba. En la medida en que la estrategia discursiva pasó a ser competencia de los nuevos asesores municipales y considerada, por tanto, un problema de "especialistas", la posibilidad de debatirla públicamente se fue cerrando. Fue curioso, sin embargo, constatar que en declaraciones del concejal de participación a periódicos locales y nacionales sobre la estrategia a seguir se mencionara el sorteo sin que apenas tuviera repercusión. Es cierto que las declaraciones no eran claras, pero lo cierto es que la estrategia fue atacada por otras vías: por puentear a las Asociaciones de Vecinos o por usar el término "jurados ciudadanos", que la oposición asoció a los "comisarios políticos" soviéticos.

\section{Críticas técnicas al sorteo: el experto de la consultora}

"El sorteo establece un ámbito cerrado para la participación, al que no pueden incorporarse las personas que lo deseen"

Este argumento conecta con la ideología de la libre participación voluntaria, pero remite a una cuestión específicamente técnica, que opone el sorteo a otros procedimientos de participación política. El sorteo tendería a limitar la participación porque impone barreras explícitas. Quien lo enuncia, no considera que las barreras implícitas y explícitas de otras formas de participación política sean relevantes, o bien piensa que pueden solventarse con innovaciones técnicas. Esta objeción no remite a principios morales -el altruismo del compromiso político- o puramente 
ideológicos -equivalencia entre democracia y elecciones-, sino que se refiere a una característica técnica del sorteo como herramienta política; no es casual que quien la formuló fuera el experto de la consultora, que tendía a trasladar la discusión al terreno de la confrontación entre distintas soluciones técnicas que se ofrecen al político en cuestión.

"La elección de representantes permite una deliberación de mayor calidad, debido al manejo de información privilegiada, en condiciones y tiempos de los que el gran público no dispone"

Esta crítica, formulada también por el experto de la consultora, remite a un cierre general del campo político tal y como está configurado en las democracias representativas modernas, apelando a una formulación particular del principio de distinción citado por Manin (1998): la separación entre representantes y representados es inevitable, en este caso por motivos de escala y por la división del trabajo. La ampliación de la participación ciudadana se suele encontrar con esta crítica como obstáculo, al considerarse que las condiciones de la deliberación para un gran número de personas son inalterables. En este sentido, la propuesta de las cámaras sorteadas con un número limitado de personas se considera positiva en tanto que mejora las condiciones de la deliberación, aunque de escasa legitimidad por su componente aleatorio y la exclusión que conlleva. Esta última observación remite al argumento mediante el cual Bernard Manin (1998, 103-118) trata de explicar el triunfo de la elección en el sistema de gobierno representativo moderno. Este sistema apela a una racionalidad con criterios flexibles que deja al libre albedrío del votante las razones por las cuales selecciona a sus representantes. De esta manera, el ejercicio del derecho al voto renueva periódicamente una legitimidad basada en el consentimiento de los gobernados frente a un modelo alternativo que se fundamenta en el derecho a "gobernar y ser gobernado por turnos" -mediante sorteo- (Aristóteles, 1977, 1317b): una legitimidad que se construye sobre la igualdad de posibilidades de ocupar cargos públicos. Pero de nuevo es significativo que se formule como una objeción específicamente técnica: lo que hace que la elección de representantes no sea preferible al sorteo no es una mayor legitimidad moral o una preferencia ideológica, sino una necesidad social "objetiva", que hace que una solución técnica sea más eficiente que otra.

Como contraste, cabe señalar que la cuestión de los presupuestos participativos -metodológica y políticamente tan problemática como el sorteo- se solventó rápidamente en la discusión; probablemente porque está más integrada en el repertorio político al uso y no cuestiona las formas tradicionales de representación, aunque hasta la fecha tampoco se ha puesto en marcha. Un dato fundamental de esta y otras reuniones es que en ningún momento se habló de la necesidad de que la asamblea aprobara cualquiera de las medidas: con el acceso al poder desapareció la necesidad de la sanción de la asamblea para aprobar propuestas y políticas, quedando el vestigio de la ratificación ritual de decisiones ya tomadas e incluso aplicadas en otras instancias. Más adelante yo mismo recurrí a la 
legitimación vía asamblearia para aprobar la propuesta de participación que defendía: podría decir que por convencimiento democrático -y así lo viví entonces-, pero sin duda puede leerse el recurso como la necesidad de legitimar una política propuesta desde una posición exterior a la institución.

\section{Cuarto hito. La legitimación de una estrategia de participación por vía asamblearia}

La agrupación estaba inmersa en una dinámica de improvisación, precipitación y falta de organización; algo que ya estaba presente antes de las elecciones, pero que se había agravado con la entrada en el Ayuntamiento. A ello se sumaba la acción coordinada de grupos organizados para controlar la asamblea, la creciente distancia entre los representantes y la base y la tendencia a consultar con "expertos" cercanos política o personalmente a quienes ocupaban los cargos, casi siempre precipitadamente y obviando a la asamblea. Esta situación generó un clima de urgencia, ineficacia y sospecha que desembocó en problemas y desafección en la agrupación.

En un intento de regular esta situación caótica y aprovechando la necesidad de coordinarse con Ganar Cádiz en Común, la coalición de izquierdas que era socio minoritario de gobierno, se nombraron unas comisiones mixtas encargadas de apoyar a los concejales y servir de enlace con las respectivas asambleas (26 de agosto de 2015). En las reuniones de la comisión mixta de participación se comenzó a acordar de manera más detallada una estrategia de participación ciudadana para el Ayuntamiento, lo que sirvió de estímulo para organizar unas jornadas de formación en Podemos que desembocaran en la discusión y aprobación de la posición del partido sobre la estrategia a seguir en ese ámbito (comenzaron a organizarse el 18 de noviembre de 2015 y se celebraron en enero de 2016). En estas jornadas se discutió ampliamente sobre la cuestión del sorteo. Estaban divididas en una formación con tres intervenciones: dos profesores universitarios y yo. Después de la formación, se organizó un debate entre dos modelos de participación: el que yo defendía, basado en el programa electoral, y el de un antiguo presidente de una federación de Asociaciones de Vecinos de Cádiz, promocionado por la antigua comisión de participación, defendiendo su propuesta de participación territorial por delegación. En este contexto, la recepción del sorteo entre el público asistente fue muy favorable. ¿Por qué ocurrió así? Podemos retomar el esquema foucaultiano de la parresía para explicar, esta vez, las condiciones favorables a esta recepción:

1. Garantías jurídicas: yo mismo me encargué de organizar la formación, a partir del lugar que ocupaba en la comisión mixta de participación y por mi cercanía al concejal y a la coordinación. Indudablemente el hecho de que yo la organizara garantizó un espacio específico para el sorteo que probablemente no hubiera existido de otra manera ${ }^{4}$. En resumen, el sorteo pudo ser expuesto con suficientes garantías porque la persona encargada de la organización del evento era favorable a la exposición del sorteo.

4 Aunque yo pueda decir y pensar que lo organicé de la manera más ecuánime posible. El ejercicio de una posición de poder se puede concretar en muchos grados diferentes. 
2. El prestigio acumulado en los meses anteriores y el hecho de que las herramientas hubieran sido incluidas en el programa electoral generaban una disposición favorable hacia la exposición del sorteo. La etiqueta de expertos y profesores universitarios también influyó en la disposición del público, que se aprestó a recibir una formación -una clase- antes que a participar en un debate político.

3. La posibilidad de anudar un determinado discurso y una experiencia -o, más exactamente, una percepción de dicha experiencia por parte del público- varía en función del contexto de comunicación. En un espacio normativizado como formativo, con una distribución muy desigual del tiempo entre emisor y receptor, y con el primero etiquetado con atributos de prestigio intelectual y político, era más fácil establecer ese pacto entre discurso y experiencia como verdad racional, aunque el contenido de la misma estuviera fuera de los márgenes habituales de la política de la agrupación. Márgenes que, por otra parte, se habían ampliado gracias al trabajo militante de los meses anteriores. Además, por motivos que expondré a continuación, los dirigentes políticos más reticentes al sorteo no estuvieron presentes en las jornadas y, por tanto, no pudieron realizar llamadas al cierre político similares a las que hicieron anteriormente.

4. Sobre el coraje poco cabe decir en una coyuntura tan favorable: lo comentado para el primer hito sigue siendo válido aquí. En esta ocasión, además, contaba con el apoyo relativo de la corriente hegemónica en la agrupación frente a la posición defendida por la antigua comisión de participación.

Esta coyuntura tan favorable al sorteo desembocó en la aprobación de la estrategia de participación ciudadana que lo incluía en su desarrollo; pero esta dependía de dos elementos fundamentales que precisamente apuntaban en sentido contrario a su puesta en práctica efectiva en el Ayuntamiento.

En primer lugar, la asamblea no tenía la capacidad -quizás sería más apropiado decir la disposición, aunque en realidad era una mezcla de ambas cosas que requeriría un análisis más detallado- en la práctica de reclamar el cumplimiento del acuerdo por parte de los representantes. No existían herramientas que permitieran canalizar el conflicto y reducir la brecha entre los representantes y la asamblea. En el hipotético caso de que algún miembro de la asamblea llevara el incumplimiento a su extremo -pedir la revocación del concejal que no acataba su mandato-, los representantes se sabían con la capacidad de lograr un voto de la asamblea contrario a su propia resolución anterior, apelando al bien común, a la confianza, a la falta de tiempo, a evitar escándalos que pudieran ser instrumentalizados por los medios y la oposición, etc. Esta desigual relación de poder permitía a los representantes más recelosos del sorteo retraerse de la discusión, evitando así abrir un conflicto innecesario, ya que mantenían el control político efectivo sobre lo que se podía o no llevar a la práctica. Por así decirlo, la asamblea producía un cierre de la deliberación (Urfalino, 2013) en falso, ya que esta continuaba en otras instancias sin ningún control por parte de la primera.

En segundo lugar, la agrupación disponía de recursos limitados. Más allá del discurso oficial, la participación ciudadana no era una prioridad para el equipo de gobierno y se entendía más bien como una forma accesoria de legitimidad para determinadas políticas defi- 
nidas de antemano ${ }^{5}$. Ocurría, sin embargo, que la agrupación no tenía militantes ni presencia suficiente en el tejido asociativo de la ciudad como para permitirse ese tipo de intervención con garantías de éxito. En esas circunstancias, el sorteo podía interpretarse como una salvaguarda frente al corporativismo de las asociaciones más activas en la ciudad, que podrían apropiarse de las herramientas de participación ciudadana en su beneficio, o frente a la instrumentalización de la participación por parte de otros partidos con más implantación en espacios como las Asociaciones de Vecinos, con cierta legitimidad mediática e institucional. En este contexto y reservándose los representantes el derecho de una aplicación parcial en función de sus necesidades políticas, el modelo que incluía el sorteo como elemento central podía ser más útil que el modelo de delegación territorial que debía contar con unas asambleas y consejos imposibles de controlar y susceptibles de volverse en contra del Gobierno municipal. Una parte de la dirección local aceptaba el sorteo, sin demasiado convencimiento, más como un medio para evitar una influencia excesiva de otras élites políticas en la participación ciudadana que por su potencial radicalmente democrático. En todo caso, al final de la etnografía, en marzo de 2016, cualquier implementación del sorteo a corto plazo parecía absolutamente descartada.

\section{Conclusiones}

He mostrado a través de estos cuatro hitos cómo la evolución de la discusión sobre el sorteo guarda una estrecha relación con las propiedades sociales y políticas de las personas implicadas en ella y con la evolución de la propia agrupación. Esta era un espacio jerarquizado y homogéneo en torno a formas de militancia características de la izquierda extra-institucional que se transformó, con la llegada al Ayuntamiento, en una organización centrada en la política institucional y mediática. Para que el sorteo tuviera cabida en su política de participación ciudadana tuvieron que concursar varias circunstancias difíciles de conciliar: que fuera promovido por personas con cierto prestigio y capacidad de influencia en la agrupación, que no supusiera un riesgo real para la corriente hegemónica y que, al mismo tiempo, ofreciera algunas soluciones prácticas a problemas que enfrentaba la organización. A pesar de ello, el sorteo ocupó un lugar importante en el debate, aunque encontró fuertes resistencias que pueden clasificarse en los siguientes tipos ideales:

1. Cierre del campo político contra el saber profano: el sorteo como dispositivo, la persona que lo propone o aquellos a quienes promociona son descalificados como "no políticos".

\section{Repliegue sobre una posición específica del campo político:}

2.1. Extrema izquierda extra-institucional: se defiende una idea voluntarista del compromiso político y se entiende la proyección hacia el exterior de la organización como una tarea de adoctrinamiento y propaganda.

5 Lo demuestran cuestiones como la representación de las asambleas de barrio reducidas a la expresión de una ideología de izquierda revolucionaria, la caracterización de determinados órganos de participación como “correas de transmisión", la voluntad de adaptar los ritmos de la transparencia en la información municipal a las necesidades políticas del gobierno o el hecho de condicionar la implementación de herramientas como el referéndum a las necesidades políticas de la agrupación. En definitiva, la instrumentalización de la participación. 
2.2. Partidos políticos: se defiende la legitimidad superior de los partidos como agentes políticos fundamentales de la democracia representativa y la posición que en ellos ocupan quienes los defienden. La estrategia mediática es un caso específico de este tipo, que reserva un lugar privilegiado a los especialistas en la producción del discurso.

2.3. Instituciones públicas: la gestión de las instituciones introduce argumentos técnicos y de oportunidad que solo suelen estar al alcance de los gestores, contribuyendo a legitimar las jerarquías estructurales, nuevas y preexistentes.

3. Crítica técnica al sorteo: remite a una discusión específicamente técnica sobre las desventajas de este procedimiento frente a formas alternativas de participación política.

Como tipos ideales, las anteriores categorías no operan tal cual en la práctica. Toda crítica técnica conlleva una ideología determinada y, a la inversa, el rechazo ideológico al sorteo supone la afirmación de técnicas alternativas. Por otra parte, conviene recordar que las distintas posiciones políticas comentadas en este artículo dependen de una dinámica estructural: los sujetos pueden encarnar una u otra en distintos momentos, según cambien sus propiedades, la manera en que estas se perciben y el lugar que ocupan en la agrupación.

Frente a estas resistencias, el sorteo ofrecía una posible solución para regular el conflicto con otros grupos políticos organizados de la ciudad y una fuente de legitimidad adicional para una estrategia discursiva que incluía la defensa de la participación ciudadana y la democratización de las instituciones. Estos argumentos no bastaron y, finalmente, pese a formar parte del programa electoral y discutirse y aprobarse en la asamblea general, las propuestas de participación ciudadana que incluían el sorteo no se pusieron en práctica.

\section{Referencias}

Aristóteles (1977): La Política, Editora Nacional, Madrid.

Blanco, Ismael (2005): "Les jurys citoyens en Espagne. Vers un nouveau modèle de démocratie locale ?", en Marie-Hélène Bacqué, Henri Rey y Yves Sintomer (dir.): Gestion de proximité et démocratie participative, La Découverte, París.

Dowlen, Oliver y Costa Delgado, Jorge (2016): El sorteo en política: cómo pensarlo y cómo ponerlo en práctica, Editorial Doble J, Sevilla.

Eckstein, Harry (1975): "Case Studies and Theory in Political Science", en Fred Greenstein y Nelson Polsby (eds.): Handbook of Political Science, Vol. 7, Addison-Wesley, Reading, Massachusetts, pp. 79-138.

Ganuza, Ernesto (2011): "La diffusion de la démocratie délibérative dans les régions espagnoles. L'exemple du sondage délibératif sur la gestion de l'eau en Andalousie", en Yves Sintomer y Julien Talpin (dir.): La Démocratie participative au-delà de la proximité. Le Poitou-Charentes mis en perspective, PUR, Rennes.

Ibáñez, Jesús (1986): "Perspectivas de la investigación social: el diseño en la perspectiva estructural”, en Manuel García Ferrando, Jesús Ibáñez y Francisco Alvira (comp.): El análisis de la realidad social. Métodos y técnicas de investigación, Alianza Editorial, Madrid, pp. 31-66. 
López-Guerra, Claudio (2015): "La política de la suerte", en Tribuna Milenio, México, [http://www.milenio.com/tribunamilenio/a_rio_revuelto-_ganancia_de_morena/Morenaelecciones_Morena-candidatos_Morena-AMLO-Lopez_Obrador_13_474082588.html], consultado el 20 de agosto de 2017.

Manin, Bernard (1998): Los principios del gobierno representativo, Alianza Editorial, Madrid.

Moreno Pestaña, José Luis (2011): "Pensar la palabra libre con Michel Foucault: una etnografía de las asambleas del 15-M”, en Pasajes: Revista de pensamiento contemporáneo, pp. 89-99.

Por Cádiz sí se puede (2015): Programa Elecciones municipales 2015, Cádiz, [https:// porcadiz-sisepuede.info/wp-content/uploads/2015/05/PROGRAMA.pdf], consultado el 10 de mayo de 2017.

Sintomer, Yves (2011): Petite histoire de l'expérimentation démocratique. Tirage au sort et politique d'Athènes à nos jours, Éditions La Découverte, París.

Urfalino, Philippe (2013): Cerrar la deliberación. Teoría de la decisión colectiva, Prometeo Libros, Buenos Aires. 
